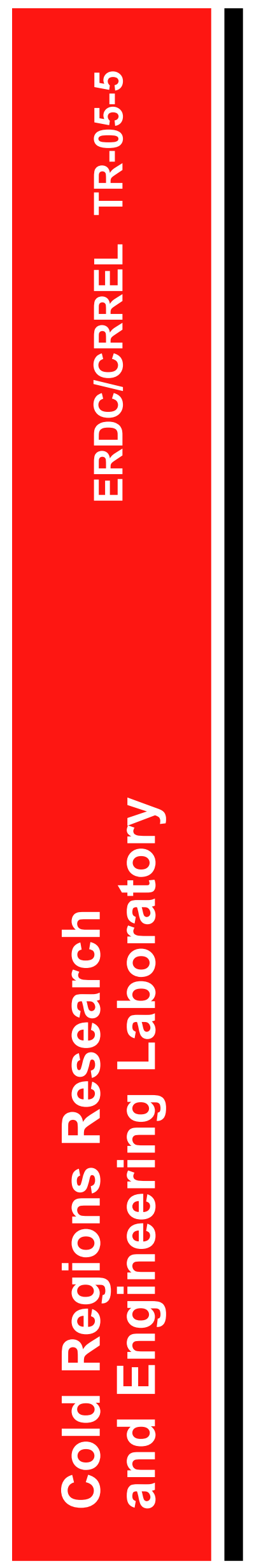

\title{
Effect of Acetonitrile on RDX Biodegradation in an Unsaturated Surface Soil
}

David B. Ringelberg, Charles M. Reynolds, Lawrence B. Perry, and Karen L. Foley 
ERDC/CRREL TR-05-5

March 2005

\section{Effect of Acetonitrile on RDX Biodegradation in an Unsaturated Surface Soil}

David B. Ringelberg, Charles M. Reynolds, Lawrence B. Perry, and Karen L. Foley

\section{Engineer Research and Development Center}

Cold Regions Research and Engineering Laboratory

72 Lyme Road

Hanover, New Hampshire 03755

Approved for public release; distribution is unlimited.

Prepared for OFFICE OF THE CHIEF OF ENGINEERS 


\section{ABSTRACT}

In previous work, we documented the biodegradation of hexahydro-1,3,5-trinitro-1,3,5-triazine (RDX) in an unsaturated cold-region surface soil and showed that acetonitrile (ACN) could inhibit RDX removal rates when used as a dispersant for the contaminant. Here, we document that the added ACN had an effect on microbial community development in the RDX-contaminated soil. In the absence of ACN, the soils showed a striking increase in microbial biomass and in biomarkers indicative of microfauna. A four-fold increase in the phospholipid fatty acid (PLFA) biomarkers 18:2w6 and 20:4w6 (approximately 4-16 mol $\%$ ) coincided with a greater than two-fold increase in total microbial biomass (approximately 15-35 nmol $\mathrm{g}^{-1}$ PLFA). In the presence of ACN (1\% aqueous concentration), these increases were not observed. The ACN-free soils also showed a significant decrease in PLFA biomarkers for Gram-negative bacteria (i.e., approximately $15 \mathrm{~mol} \%$ decrease in w7 monounsaturated PLFA). This decrease was not observed in soils amended with $1 \%$ ACN. We concluded that the organic solvent interfered with microbial community development, specifically the trophic interaction between free-living protozoa and Gram-negative bacteria. Since the addition of $1 \%$ ACN increased the half-life for RDX from 29 to 48 days, the trophic interaction may be a necessary component in the development of an RDX-biodegrading microbial community.

DISCLAIMER: The contents of this report are not to be used for advertising, publication, or promotional purposes. Citation of trade names does not constitute an official endorsement or approval of the use of such commercial products. All product names and trademarks cited are the property of their respective owners. The findings of this report are not to be construed as an official Department of the Army position unless so designated by other authorized documents. 


\section{CONTENTS}

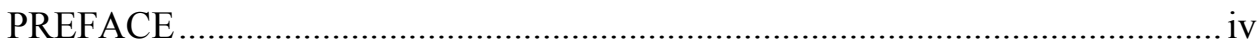

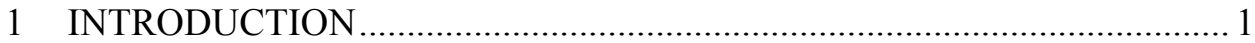

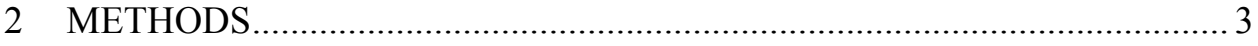

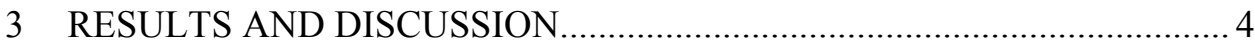

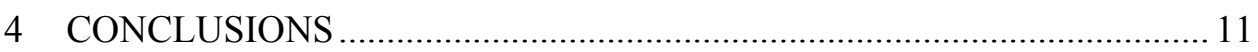

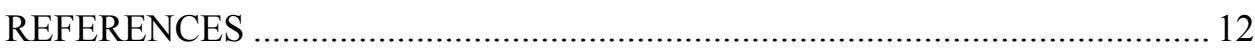

\section{ILLUSTRATIONS}

Figure 1. Mean soil RDX concentrations vs. time for the five treatments examined: $\mathrm{RDX}+0 \% \mathrm{ACN}, \mathrm{RDX}+0.1 \% \mathrm{ACN}, \mathrm{RDX}+1.0 \% \mathrm{ACN}$, $\mathrm{RDX}+0 \% \mathrm{ACN}$ autoclaved, and $\mathrm{RDX}+1.0 \% \mathrm{ACN}$ autoclaved 4

Figure 2. Data from Figure 1 presented as the rate of RDX removal

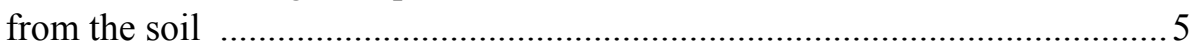

Figure 3. Total PLFA concentrations for the various treatments .......................... 6

Figure 4. PLFA biomarkers summed and used to monitor changes in specific microbial functional groups over time for the various treatments ................. 7

Figure 5. Photomicrographs of protozoa observed in the training range soil ....... 8

Figure 6. PLFA biomarkers for Gram-negative prokaryotes using different pathways for PLFA synthesis vs. treatment and sampling time 9

Figure 7. Cumulative amount of $\mathrm{CO}_{2}$ respired vs. time for the various treatments. Increasing concentrations of ACN resulted in significantly increased amounts of $\mathrm{CO}_{2}$ respired

\section{TABLE}

Table 1. RDX concentration in unsaturated soil microcosms amended with $0 \%, 0.1 \%$, and $1 \%$ acetonitrile and $10 \mathrm{mg} \mathrm{kg}^{-1} \mathrm{RDX}$ 


\section{PREFACE}

This report was prepared by David B. Ringelberg, Research Physical Scientist; Dr. Charles M. Reynolds, Research Physical Scientist; Lawrence B. Perry, Lead Physical Sciences Technician; and Karen L. Foley, Biological Science Technician, all of the Environmental Sciences Branch, Cold Regions Research and Engineering Laboratory (CRREL), U.S. Army Engineer Research and Development Center (ERDC), Hanover, New Hampshire.

The authors thank Dr. Thomas Jenkins and Marianne Walsh. Without their technical assistance and insight, this work would not have been possible. They also acknowledge the assistance of Lauren Raymond in sample preparation. This work was funded through the U.S. Army Engineer Research and Development Center, Environmental Laboratory, Basic Research Program Office, administered by Dr. John Cullinane.

This report was prepared under the general supervision of Lawrence Gatto, Acting Chief, Environmental Sciences Branch; Dr. Lance Hansen, Deputy Director; and James L. Wuebben, Acting Director, CRREL.

The Commander and Executive Director of the Engineering Research and Development Center is COL James R. Rowan. The Director is Dr. James R. Houston. 


\title{
Effect of Acetonitrile on RDX Biodegradation in an Unsaturated Surface Soil
}

\author{
DAVID RINGELBERG, CHARLES M. REYNOLDS, \\ LAWRENCE B. PERRY, AND KAREN L. FOLEY
}

\section{INTRODUCTION}

In a previous study, we demonstrated that RDX biodegradation proceeded at a rate seven times faster under water-saturated versus unsaturated soil conditions (Ringelberg et al. 2003). We also showed that the enhanced rate of RDX biotransformation in the saturated soil was associated with the development of a unique microbial community composition (Ringelberg et al. 2005). The watersaturated soils supported the development of a microbial community enriched in firmicutes and the alpha and delta classes of the proteobacteria. Species of the genera Clostridia, Rhodococcus, and Beijerinckia were specifically identified. All three of these genera contain species known to biodegrade/transform RDX (Bhushan et al. 2003, Seth-Smith et al. 2002). ${ }^{*}$ The microbiota within the unsaturated soils developed along a different path, showing enrichment in gammaproteobacteria and microeukaryotes, with no single organism being identified with a known capability to degrade RDX. It was concluded that soil moisture tension was a defining factor in the development of the soil microbial communities and that the resulting communities were either primed for RDX biodegradation (i.e. saturated) or not (i.e. unsaturated).

Others have reported that unsaturated surface soils of varying geochemical parameters can hold RDX for very long periods of time (Miyares and Jenkins 2000). Yet some aerobic surface soils, such as the Alaskan soil studied here, show relatively short half-lives for RDX. Speitel et al. (2001) showed that the rate of RDX loss in an unsaturated surface soil was significantly affected by the addition of carbon and nutrients. Trophic interactions can also play a substantial role in microbial community development in the presence of xenobiotics. An increasing number of publications are identifying a direct role of protozoa in the

\footnotetext{
*Also personal communication, Dr. Neal Adrian and Dr. Herb Fredrickson, ERDC.
} 
biodegradation of organic pollutants (Kinner et al. 1998, 2002, Zarda et al. 1998, Cox et al. 1999, Bouchez et al. 2000, Mattison and Harayama 2001). Of particular interest is the work of Mattison and Harayama (2001), who showed an increase in toluene degradation rates $\left(0.37\right.$ to $\left.1.38 \mathrm{fmol} \mathrm{cell}^{-1} \mathrm{~h}^{-1}\right)$ by Pseudomonas sp. strain PS+ in the presence of a soil flagellate. The results from these studies indicate that a variety of factors and inputs can affect the biodegradation of RDX in a surface soil.

In this report we describe certain consequences of using the organic solvent acetonitrile as a dispersant for RDX. Our previous work showed that acetonitrile, at $1 \%$ final volume in an unsaturated soil, inhibited RDX biodegradation by a factor of two. Here we show that the presence of acetonitrile also had a significant effect on microbial community development within the soil microcosms. The effect of ACN on the in situ microbiota was quantified by examination of phospholipid fatty acid (PLFA) profile changes over time. We considered scenarios where ACN acted as a toxicant and as an available source of carbon and/or nitrogen. We did not anticipate the finding that trophic interactions might have played a pivotal role in the development of an RDX-biodegrading microbial community within this surface soil. 


\section{METHODS}

The surface soil used in this study was obtained from a training area within Ft. Greely, Alaska. The soil was passed through a $4.7-\mathrm{mm}$ sieve and then hand mixed and air-dried at $45^{\circ} \mathrm{C}$ for 18 hours. The processed soil had a texture of $58 \%$ sand, $35 \%$ silt, $7 \%$ clay, a $\mathrm{pH}$ of 6.7 , an organic matter content of $10.4 \%$ (on a dry weight basis), $\mathrm{NO}_{3}-\mathrm{N}$ at $4 \mathrm{mg} \mathrm{kg}^{-1}, \mathrm{NH}_{4}-\mathrm{N}$ at $5 \mathrm{mg} \mathrm{kg}^{-1}$, phosphorus at 4 $\mathrm{mg} \mathrm{kg}{ }^{-1}$, potassium at $34 \mathrm{mg} \mathrm{kg}^{-1}$, and $\mathrm{Fe}$ at $0.25 \mathrm{mg} \mathrm{kg}^{-1}$. Individual soil microcosms were equilibrated by pre-incubation for 48 hours at $21^{\circ} \mathrm{C}\left( \pm 2^{\circ} \mathrm{C}\right)$ at a soil moisture tension of 0.015 bar. Triplicate microcosms each received $5 \mathrm{~g}$ of soil (dry weight) and $1.43 \mathrm{~mL}$ of $\mathrm{H}_{2} \mathrm{O}$ (Milli-Q grade), or $0 \% \mathrm{ACN} ; 1.428 \mathrm{~mL}$ of $\mathrm{H}_{2} \mathrm{O}$ plus $2 \mu \mathrm{L}$ of $\mathrm{ACN}$ (Burdick and Jackson, Muskeegon, WI), or $0.1 \% \mathrm{ACN}$; or $1.405 \mathrm{~mL}$ of $\mathrm{H}_{2} \mathrm{O}$ and $25 \mu \mathrm{L}$ of ACN, or $1.0 \%$ ACN. Following the preincubation, each microcosm received $0.57 \mathrm{~mL}$ of aqueous $\mathrm{RDX}\left(35 \mathrm{mg} \mathrm{L}^{-1}\right)$. Control (attenuated) microcosms were autoclaved at $120^{\circ} \mathrm{C}$ for 20 minutes three times, with an 8-hour resting period between autoclaving.

Microcosms were incubated in the dark at room temperature $\left(21^{\circ} \mathrm{C} \pm 2^{\circ} \mathrm{C}\right)$ for a total of 840 hours without agitation. Three replicate vials were sacrificed at 0 , $48,168,504$, and 840 hours to obtain microbiological and contaminant data. RDX concentrations in the soils were quantified as described in detail in Ringelberg et al. (2003). Briefly, soils were extracted in ACN for 18 hours with sonication at $15^{\circ} \mathrm{C}$. Then $1 \mathrm{~mL}$ of the supernatant was analyzed on a $\mathrm{C} 8$ reverse-phase HPLC column. RDX was eluted in isopropanol:water (15:85, v:v) and detected by $\mathrm{UV}$ at $254 \mathrm{~nm}$. Microbiological analyses were as described in Ringelberg et al. (2005). Phospholipid fatty acids (PLFAs) were recovered from the soils using the method of White and Ringelberg (1998). Microbial respiration was measured on a Columbus Instruments respirometer (Columbus, $\mathrm{OH}$ ) as $\mathrm{CO}_{2}$ off-gas in the headspace of a closed vessel that refreshed every 4 minutes with compressed air containing no $\mathrm{CO}_{2}$. Headspace $\mathrm{CO}_{2}$ was measured above the microcosms during the 48-hour pre-incubation period and plotted as a cumulative concentration ( $\mu \mathrm{g}$ $\mathrm{CO}_{2} \mathrm{~g}^{-1}$ soil).

Analyses of variance (ANOVA) were conducted on PLFA molar percentages using commercial software (Statistica v.6.0, StatSoft, Inc., Tulsa, OK). Post hoc analyses for significance $(\alpha=0.05)$ were made using the Tukey honest significant difference method. 


\section{RESULTS AND DISCUSSION}

The soil used in this study had a demonstrated capacity for biological transformation of RDX (Ringelberg et al. 2003). In previous work, we reported a $100 \%$ loss in the parent RDX moiety after 504 hours of incubation under a saturated condition and a 58\% loss after 840 hours under an unsaturated condition ( 0.15 bar). The observed loss in RDX was attributed to biotic processes because significant microbial biomarker differences were detected between the controls and the active treatments at both soil water potentials. In the unsaturated soil, acetonitrile added to a final concentration of $1 \%$ was found to significantly inhibit RDX biotransformation (Fig. 1). The half-life for RDX in the presence of $1 \%$ acetonitrile was 48 days, nearly twice that when acetonitrile was present at or below a final concentration of $0.1 \%$ (i.e. 29 days). However, a significant loss in RDX concentration was not observed until 504 hours into the incubation (Table 1). A plot of the rate at which RDX was removed from the soil indicated that the greatest change was at 504 hours and in particular at 840 hours (Fig. 2). It was at the final time point that the greatest shift in microbial community composition was observed.

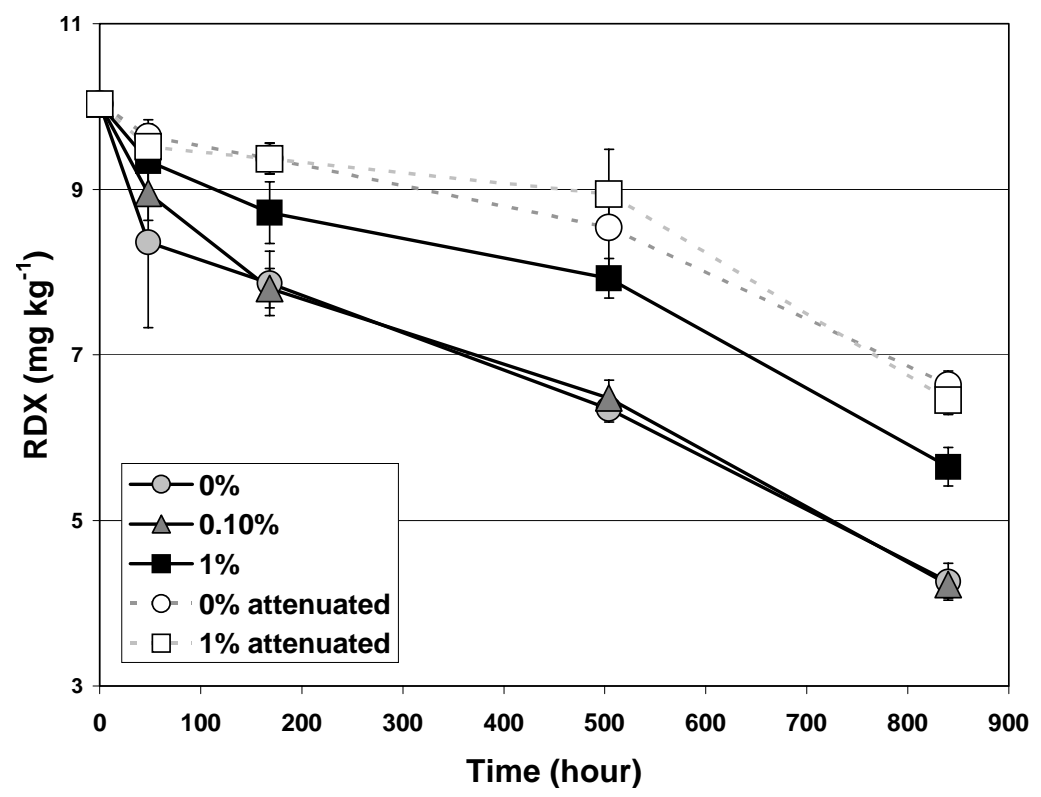

Figure 1. Mean $(n=3)$ soil RDX concentrations vs. time for the five treatments examined: RDX $+0 \%$ ACN, RDX $+0.1 \%$ ACN, RDX + 1.0\% ACN, RDX + 0\% ACN autoclaved, and RDX $+1.0 \% A C N$ autoclaved. The results indicate that RDX loss from the non-sterilized soils was inhibited by the addition of $1.0 \%$ ACN. Errors bars indicate one standard deviation. 
Table 1. RDX concentration in unsaturated ( 0.15 bar) soil microcosms amended with $0 \%, 0.1 \%$, and $1 \%$ acetonitrile and $10 \mathrm{mg}$ $\mathrm{kg}^{-1}$ RDX. Attenuated controls were autoclaved three times, with 8-hour resting periods between sterilizations.

\begin{tabular}{|lcccc|}
\hline & \multicolumn{4}{c|}{ RDX concentration $\left(\mathbf{m g ~ k g ~}^{\mathbf{- 1}}\right.$ ) } \\
\cline { 2 - 5 } \multicolumn{1}{c}{ ACN (\%) } & 48 hours & $\mathbf{1 6 8}$ hours & $\mathbf{5 0 4}$ hours & $\mathbf{8 4 0}$ hours \\
\hline 0 & $8.4 \mathrm{~A}^{*}$ & $7.9 \mathrm{AB}$ & $6.3 \mathrm{~A}$ & $4.3 \mathrm{~A}$ \\
0.1 & $8.9 \mathrm{~A}$ & $7.8 \mathrm{~A}$ & $6.5 \mathrm{~A}$ & $4.2 \mathrm{~A}$ \\
1.0 & $9.3 \mathrm{~A}$ & $8.7 \mathrm{AB}$ & $7.9 \mathrm{~B}$ & $5.6 \mathrm{~B}$ \\
0, attenuated & $9.6 \mathrm{~A}$ & $9.4 \mathrm{~B}$ & $8.5 \mathrm{BC}$ & $6.6 \mathrm{C}$ \\
1.0, attenuated & $9.5 \mathrm{~A}$ & $9.4 \mathrm{~B}$ & $8.9 \mathrm{C}$ & $6.5 \mathrm{C}$ \\
\hline
\end{tabular}

${ }^{*}$ Means with the same letter are not significantly different $(p \leq 0.05)$; Tukey HSD.

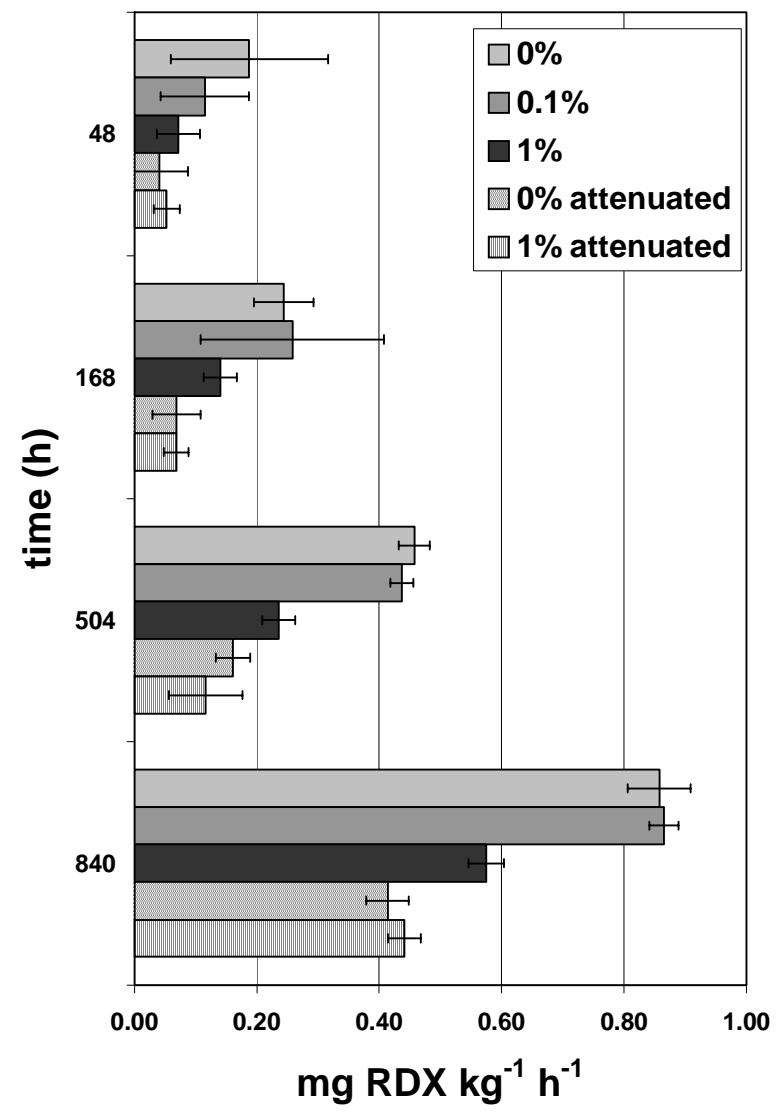

Figure 2. Data from Figure 1 presented as the rate of RDX removal from the soil. The greatest rate of RDX loss from the soils occurred at 840 hours. 


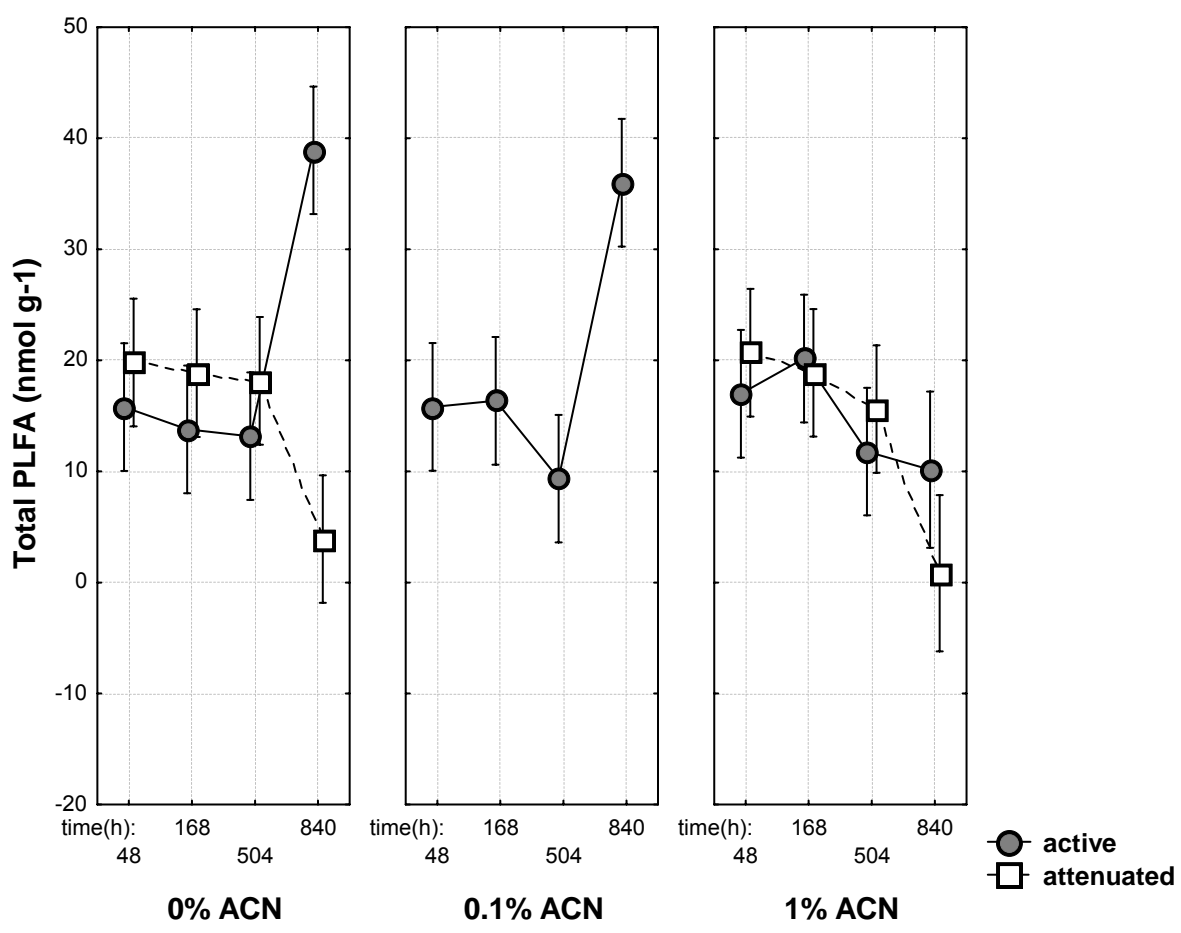

Figure 3. Total PLFA concentrations for the various treatments. PLFA concentration is used here as a measure of the total viable microbial biomass present in each soil microcosm. The microbial biomass was found to increase significantly between 540 and 804 hours of incubation when the soils were amended with $0.1 \%$ ACN or less. The treatments are as described in Figure 1. Least square means $(n=3)$ are plotted against time, with vertical bars indicating 0.95 confidence intervals.

Changes in microbial biomass were monitored by measuring PLFA concentrations over time (Fig. 3). All living cells are surrounded by a membrane containing polar lipids. Phospholipids are typically the most abundant of the polar lipids and, upon cell lysis (or cell death), become exposed to endogenous and exogenous phospholipases. The phospholipids are typically degraded within hours following cell death, making them ideal biomarkers for quantifying the living biomass (White et al. 1979). The only significant change in microbial biomass was recorded after 840 hours of incubation (Fig. 3). Between the 540- and 840-hour sampling points, microbial biomass increased nearly two and half times when $\mathrm{ACN}$ was present at $0.1 \%$ or less. The $1 \% \mathrm{ACN}$ exposure limited microbial biomass to a level similar to that measured in the attenuated controls.

Similar to total microbial biomass, differences in PLFA biomarkers representative of specific microbial taxonomic groups were found to be significantly different only at the final time point and at $\mathrm{ACN}$ concentrations of less than $1.0 \%$ 


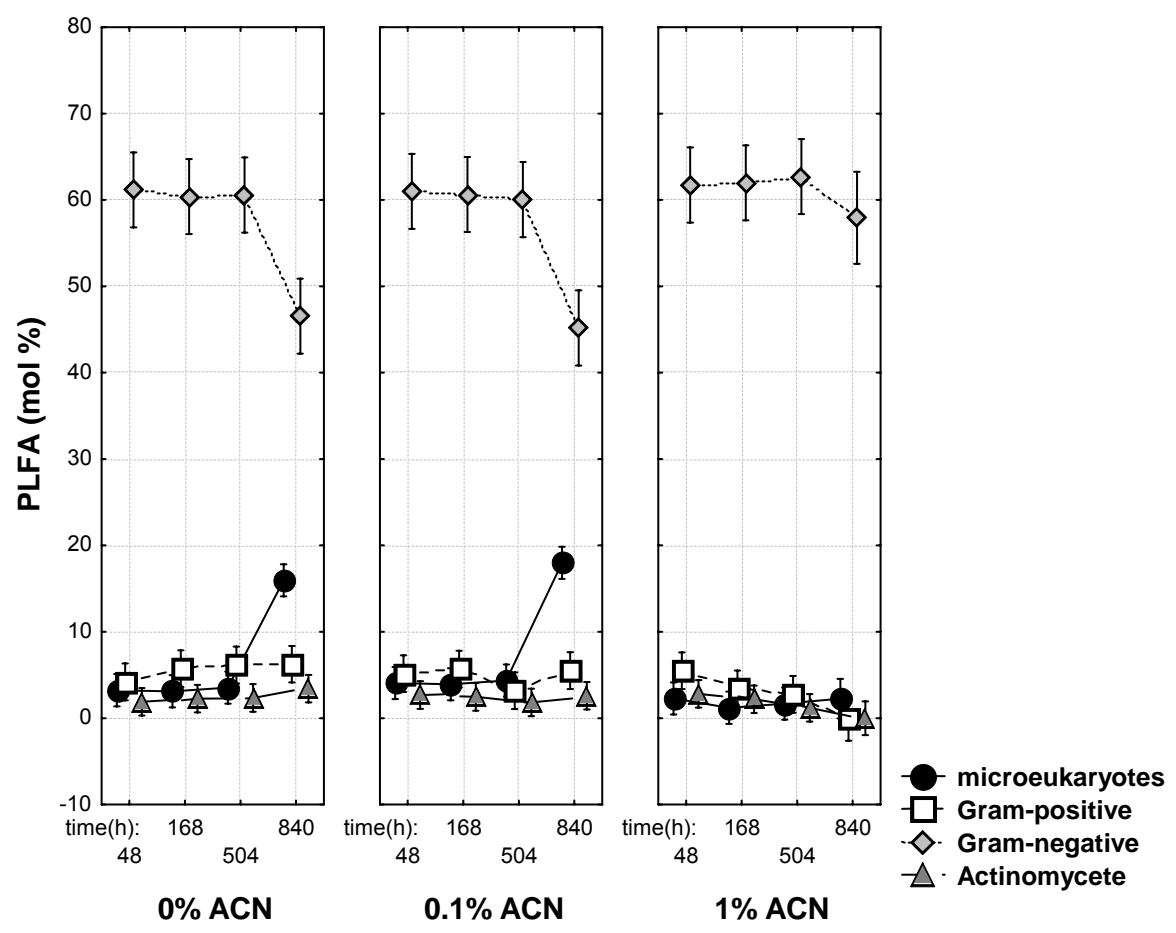

Figure 4. PLFA biomarkers summed and used to monitor changes in specific microbial functional groups over time for the various treatments. The functional groups identified in the soil microcosms and defining PLFAs were microeukaryotes (di- and polyunsaturated PLFAs), Gram-positive prokaryotes (terminally branched saturated PLFAs), Gram-negative prokaryotes (monounsaturated PLFAs), and actinomycetes (terminally branched monounsaturated PLFAs). Between 540 and 804 hours of incubation, there was a dramatic change in the microeukaryotic and Gram-negative prokaryote functional groups. The treatments are as described in Figure 1. Least square means $(n=3)$ are plotted against time, with vertical bars indicating 0.95 confidence intervals.

(Fig. 4). The PLFA assay is commonly used to taxonomically identify microorganisms based on unique PLFA signatures (White and Ringelberg 1998). In community analyses, quantified PLFA profiles can be used to define taxonomic responses to contaminant exposures (Ringelberg et al. 2001). Between 504 and 840 hours of incubation, signature PLFA biomarkers indicative of microeukaryotes increased by $12-14 \%$ whereas biomarkers for Gram-negative prokaryotes decreased by $14-15 \%$ (Fig. 4). No significant change in the percentages of any of the taxonomic groups was measured for the $1 \%$ ACN exposure.

The microeukaryotic PLFA biomarkers detected included $\omega 3$ and $\omega 6$ fatty acids, which represent microflora and microfauna, respectively (Lechevalier and 


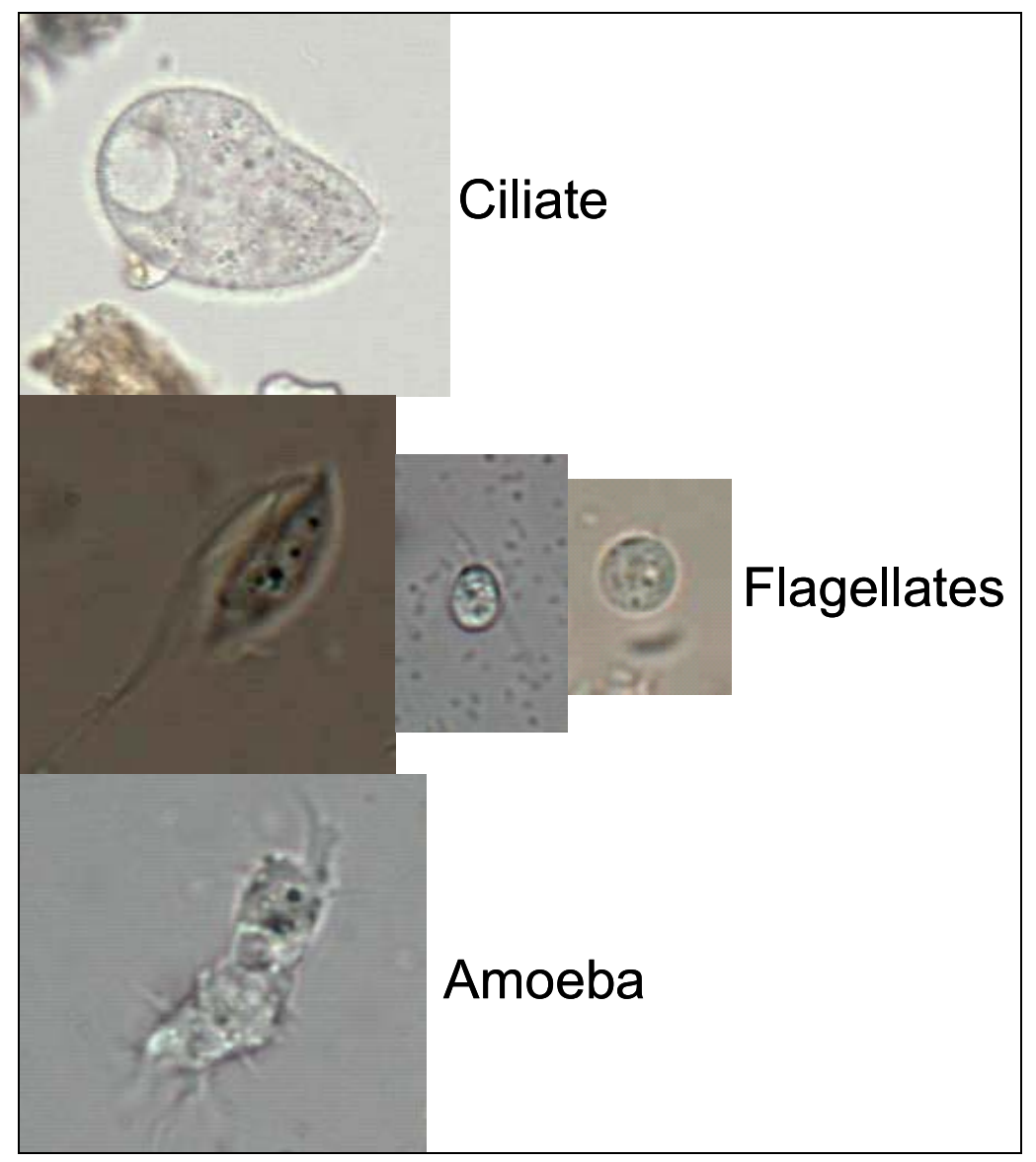

Figure 5. Photomicrographs of protozoa observed in the training range soil. All images were taken at $40 \times$ and contrast- and size-adjusted for best viewing.

Lechevalier 1988). The $\omega 6$ PLFA were reported to be at least ten times more abundant than the 13 PLFA (Ringelberg et al. 2004). Visual inspection of the soil revealed an abundance of ciliates, amoeba, and flagellates (Fig. 5). Flagellates in the size range of 10-30 $\mu \mathrm{m}$ were by far the most abundant (data not shown). Ronn et al. (2002) suggested that medium-sized Gram-negative bacteria are often preferentially grazed over other bacterial types. In this study, we found that as the eukaryotic biomarkers increased, there was a corresponding decrease in the abundance of Gram-negative PLFA biomarkers (Fig. 4). The decrease was primarily in those bacteria utilizing the anaerobic desaturase pathway for PLFA biosynthesis terminating in the $\omega 7$ series of monounsaturated PLFA (Fig. 6). No significant change was observed among the $\omega 5, \omega 8$, or $\omega 9$ series, which are monounsaturated PLFAs derived via aerobic desaturation. Additionally, no significant loss in Gram-positive bacterial PLFA biomarkers was measured in any 


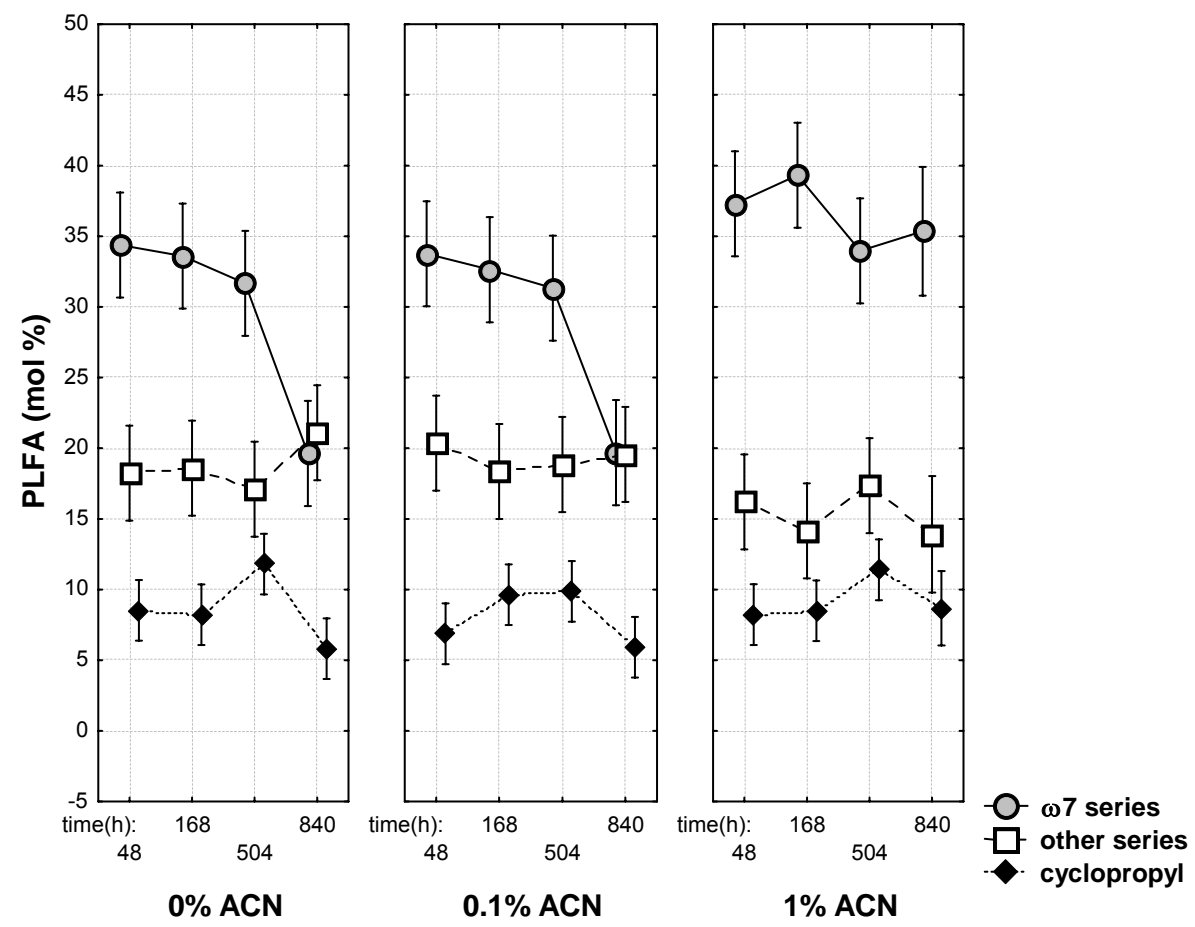

Figure 6. PLFA biomarkers for Gram-negative prokaryotes using different pathways for PLFA synthesis vs. treatment and sampling time. The three pathways identified were: anaerobic desaturation, including the $\omega 7$ series

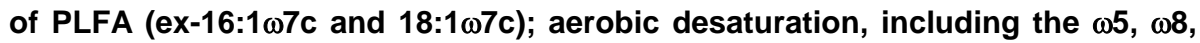
and $\omega 9$ (or other) series of PLFA (ex- 16:1 $\omega 5,17: 1 \omega 8$, and 18:1 $\omega 9$ ); and the formation of cyclopropyl PLFA (ex cy17:0 and cy19:0). The only series to show a significant change over the time of the study was the $\omega 7$ series. The treatments are as described in Figure 1. Least square means $(n=3)$ are plotted against time, with vertical bars indicating 0.95 confidence intervals.

treatment. The differential response within the Gram-negative bacterial community and the lack of any significant change within the Gram-positive bacterial community supports the idea that size-selective grazing may have occurred.

Protozoan grazing can lead to increased bacterial activity within the population of bacteria being grazed. Mattison and Harayama (2001) showed that the rate of toluene degradation by Pseudomonas sp. strain PS+ was as much as 7.5 times greater in the presence of the bacterivorous flagellate Heteromita globosa. In this study, an inverse relationship was observed between PLFA biomarkers for microfauna and Gram-negative specific bacterial biomarkers ( $\omega 7$ monounsaturates). The increase in the percentage of protozoan biomarkers and concurrent decrease in Gram-negative biomarkers correlated with increased rates of loss of RDX from the microcosm soil. Although protozoan grazing can also lead to the 
decimation of specific populations of bacteria, resulting in adverse effects on biodegradation activity (Bouchez et al. 2000), the $\omega 7$ biomarkers remained at a substantial level throughout the incubation period (Fig. 6).

Certain bacteria-Acinetobacter, Pseudomonas, Aeromonas, and Nocardia bacterial sp. - have also been shown to be capable of acetonitrile biodegradation (U.S. EPA 1985, Nawaz et al. 1989). During the pre-incubation period, amendments of increasing ACN concentrations resulted in increased rates of respiration (Fig. 7). This result suggests that ACN may have served as an alternative carbon and/or nitrogen source for microbial metabolism. Coleman et al. (1998) showed that alternative sources of organic nitrogen can interfere with RDX biodegradation. However, microbial biomass was not significantly different between treatments at the start of the incubation period (Fig. 3). In addition, the 48-hour sampling period did not show a significant enrichment in any of the microbial functional groups described in Figure 4. Although ACN at 1\% final volume may have induced an initial increase in microbial respiration, this effect did not translate into an effect on microbial community composition nor on the measured rate of RDX loss (Fig. 2).

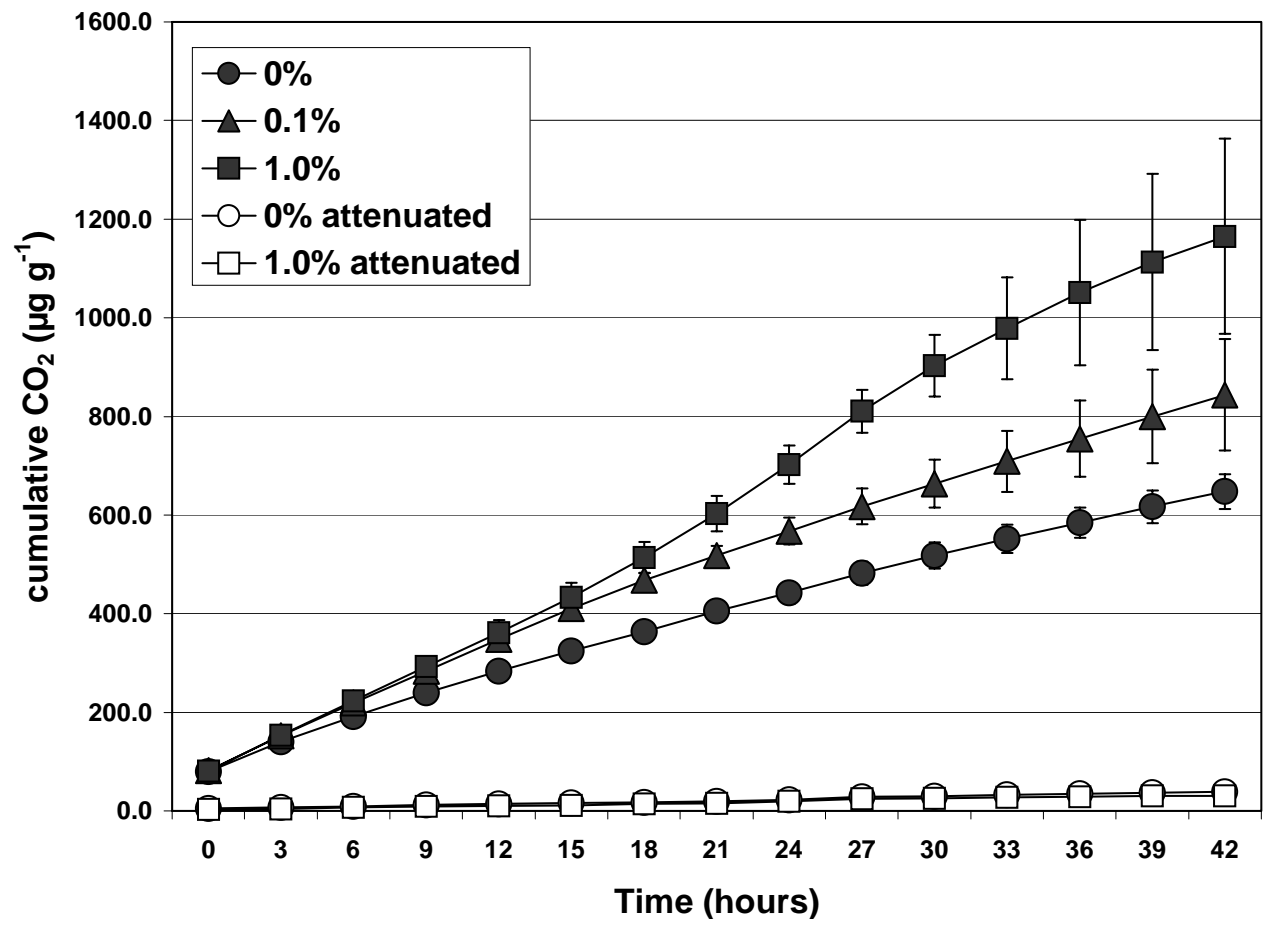

Figure 7. Cumulative amount of $\mathrm{CO}_{2}$ respired vs. time for the various treatments. Increasing concentrations of $\mathrm{ACN}$ resulted in significantly increased amounts of $\mathrm{CO}_{2}$ respired. The treatments are as described in Figure 1. Error bars represent one standard deviation. 


\section{CONCLUSIONS}

Whether by the addition of an alternative carbon and or nitrogen source or by the inhibition of trophic interactions, the addition of acetonitrile to a soil to a final concentration of $1 \%$ significantly reduced in situ rates of RDX biotransformation over an 840-hour period. Careful consideration should be given to the use of any organic solvent as a contaminant dispersant in a soil when designing biotreatability studies to estimate rates of contaminant loss. 


\section{REFERENCES}

Bouchez, T., D. Patureau, P. Dabert, S. Juretschko, J. Dore, P. Deelgenes, R. Moletta, and M. Wagner (2000) Ecological study of a bioaugmentation failure. Environmental Microbiology, 2(2): 179-190.

Bhushan, B., S. Trott, J.C. Spain, A. Halasz, L. Paquet, and J. Hawari (2003) Biotransformation of hexahydro-1,3,5-trinitro-1,3,5-triazine (RDX) by a rabbit liver cytochrome P450: Insight into the mechanism of RDX biodegradation by Rhodococcus sp. strain DN22. Applied Environmental Microbiology, 69: 1347-1351.

Coleman, N.V., D.R. Nelson, and T. Duxbury (1998) Aerobic biodegradation of hexahydro-1,3,5-trinitro-1,3,5-triazine (RDX) as a nitrogen source by a Rhodococcus sp., strain DN22. Soil Biology and Biochemistry, 30: 1159-1167.

Cox, H.H.J., N.T. Nguyen, and M.A. Deshusses (1999) Predation of bacteria by the protozoa Tetrahymena pyriformis in toluene-degrading cultures. Biotechnology Letters, 21(3): 235-239.

Kinner, N.E., R.W. Harvey, K. Blakeslee, G. Novarino, and L.D. Meeker (1998) Size-selective predation on groundwater bacteria by nanoflagellates in an organic-contaminated aquifer. Applied Environmental Microbiology, 64(2): 618625.

Kinner, N.E., R.W. Harvey, D.M. Shay, D.W. Metge, and A. Warren (2002) Field evidence for a protistan role in an organically-contaminated aquifer. Environmental Science and Technology, 36(20): 4312-4318.

Lechevalier, H., and M.P. Lechevalier (1988) Chemotaxonomic use of lipids An overview. In Microbial Lipids (C. Ratledge and S.G. Wilkinson, ed.). Volume 1. San Diego, California: Academic Press, p. 869-902.

Mattison, R.G., and S. Harayama (2001) The predatory soil flagellate Heteromita globosa stimulates toluene biodegradation by a Pseudomonas sp. FEMS Microbiology Letters, 194(1): 39-45.

Miyares, P.H., and T.F. Jenkins (2000) Estimating half lives of key components of the chemical vapor signature of land mines. Technical Report ERDC/CRREL TR-00-17, U.S. Army Engineering Research and Development Center, Cold Regions Research and Engineering Laboratory, Hanover, New Hampshire.

Nawaz, M.S., K.C. Chapatwala, and J.H. Wolfram (1989) Degradation of acetonitrile by Pseudomonas putida. Applied Environmental Microbiology, 55: $2267-2274$. 
Ringelberg, D.B., J.W. Talley, E.J. Perkins, S.G. Tucker, R.G. Luthy, E.J. Bower, and H.L. Fredrickson (2001) Succession of phenotypic, genotypic and metabolic community characteristics during the in vitro bioslurry treatment of PAH-contaminated sediments. Applied Environmental Microbiology, 67(4): $1542-1550$.

Ringelberg, D.B., C.M. Reynolds, M.E. Walsh, and T.F. Jenkins (2003) RDX loss in a surface soil under saturated and well drained conditions. Journal of Environmental Quality, 32: 1244-1249.

Ringelberg, D.B., C.M. Reynolds, K.L. Foley, and L.B. Perry (2005) Microbial community shifts associated with RDX loss in a saturated and well-drained surface soil. Technical Report ERDC/CRREL TR-05-??, U.S. Army Engineering Research and Development Center, Cold Regions Research and Engineering Laboratory, Hanover, New Hampshire.

Ronn, R., A.E. McCaig, B.S. Griffiths, and J.I. Prosser (2002) Impact of protozoan grazing on bacterial community structure in soil microcosms. Applied Environmental Microbiology, 68(12): 6094-6105.

Seth-Smith, H.M.B., S.J. Rosser, A. Basran, E.R. Travis, E.R. Dabbs, S. Nicklin, and N.C. Bruce (2002) Cloning, sequencing, and characterization of the hexahydro-1,3,5-trinitro-1,3,5-triazine degradation gene cluster from Rhodococcus rhodochrous. Applied Environmental Microbiology, 68: 47644771.

Speitel, G.E., T.L. Engels, and D.C. McKinney (2001) Biodegradation of RDX in unsaturated soil. Bioremediation Journal, 5(1): 1-11.

U.S. EPA (1985) Health and environmental effects profile for acetonitrile. Report ECAO-CIN-P137, U.S. Environmental Protection Agency, Office of Research and Development, Washington, D.C.

White, D.C., W.M. Davis, J.S. Nickels, J.D. King, and R.J. Bobbie (1979) Determination of the sedimentary microbial biomass by extractable lipid phosphate. Oecologia, 40: 51-62.

White, D.C., and D.B. Ringelberg (1998) Signature lipid biomarker analysis. In Techniques in Microbial Ecology (R.S. Burlage, R. Atlas, D. Stahl, G. Geesey, and G. Sayler, ed.). New York: Oxford University Press, p. 255-272.

Zarda, B., G. Mattison, A. Hess, D. Hahn, P. Hohener, and J. Zeyer (1998) Analysis of bacterial and protozoan communities in an aquifer contaminated with monoaromatic hydrocarbons. FEMS Microbiological Ecology, 27(2): 141-152. 


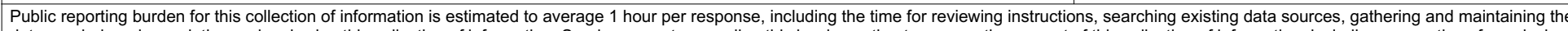

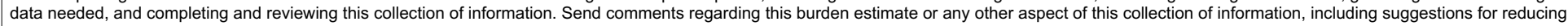

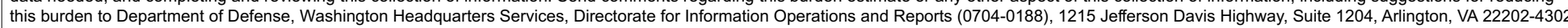

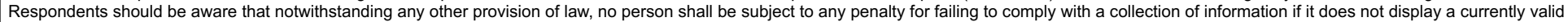
OMB control number. PLEASE DO NOT RETURN YOUR FORM TO THE ABOVE ADDRESS.
1. REPORT DATE (DD-MM-YY)
March 2005
2. REPORT TYPE
Technical Report

4. TITLE AND SUBTITLE

Effect of Acetonitrile on RDX Biodegradation in an Unsaturated Surface Soil
3. DATES COVERED (From - To)

5a. CONTRACT NUMBER

5b. GRANT NUMBER

5c. PROGRAM ELEMENT NUMBER

5d. PROJECT NUMBER

5e. TASK NUMBER

5f. WORK UNIT NUMBER

8. PERFORMING ORGANIZATION REPORT

ERDC/CRREL TR-05-5

10. SPONSOR / MONITOR'S ACRONYM(S)

11. SPONSOR / MONITOR'S REPORT NUMBER(S)

U.S. Army Corps of Engineers

Washington, DC 20314-1000

\section{DISTRIBUTION / AVAILABILITY STATEMENT}

Approved for public release; distribution is unlimited.

Available from NTIS, Springfield, Virginia 22161.

\section{SUPPLEMENTARY NOTES}

\section{ABSTRACT}

In previous work, we documented the biodegradation of hexahydro-1,3,5-trinitro-1,3,5-triazine (RDX) in an unsaturated cold-region surface soil and showed that acetonitrile $(\mathrm{ACN})$ could inhibit RDX removal rates when used as a dispersant for the contaminant. Here, we document that the added ACN had an effect on microbial community development in the RDX-contaminated soil. In the absence of ACN, the soils showed a striking increase in microbial biomass and in biomarkers indicative of microfauna. A four-fold increase in the phospholipid fatty acid (PLFA) biomarkers 18:2w6 and 20:4w6 (approximately 4-16 mol \%) coincided with a greater than two-fold increase in total microbial biomass (approximately $15-35 \mathrm{nmol} \mathrm{g}^{-1}$ PLFA). In the presence of ACN (1\% aqueous concentration), these increases were not observed. The ACN-free soils also showed a significant decrease in PLFA biomarkers for Gram-negative bacteria (i.e., approximately 15 mol\% decrease in w7 monounsaturated PLFA). This decrease was not observed in soils amended with $1 \%$ ACN. We concluded that the organic solvent interfered with microbial community development, specifically the trophic interaction between free-living protozoa and Gram-negative bacteria. Since the addition of 1\% ACN increased the half-life for RDX from 29 to 48 days, the trophic interaction may be a necessary component in the development of an RDX-biodegrading microbial community.

\begin{tabular}{|c|c|c|c|c|c|c|}
\hline 15. SUBJECT TERMS & Acetonitrile (ACN) & \multicolumn{2}{|c|}{ Hexahydro-1,3,5-trinitro-1,3,5-triazine (RDX) } & $\begin{array}{l}\text { Microbi } \\
\text { Phospho }\end{array}$ & $\begin{array}{l}\text { mmunity } \\
\text { fatty acid (P }\end{array}$ & Phospholipid fatty acid (PLFA) \\
\hline \multicolumn{3}{|c|}{ 16. SECURITY CLASSIFICATION OF: } & \multirow{2}{*}{\multicolumn{2}{|c|}{$\begin{array}{l}\text { 17. LIMITATION OF } \\
\text { OF ABSTRACT }\end{array}$}} & \multirow{2}{*}{$\begin{array}{l}\text { 18. NUMBER } \\
\text { OF PAGES }\end{array}$} & 19a. NAME OF RESPONSIBLE PERSON \\
\hline a. REPORT & b. ABSTRACT & c. THIS PAGE & & & & 19b. TELEPHONE NUMBER (include area code) \\
\hline $\mathrm{U}$ & $\mathrm{U}$ & $\mathrm{U}$ & & $\mathrm{U}$ & 19 & \\
\hline
\end{tabular}

